CDU $806.9-318(816.5)$

\title{
OS PRIMEIROS GLOSSÃRIOS SOBRE O LINGUAJAR GAÚCHO
}

\author{
HEINRICH A. W. BUNSE \\ Doutor em Letras Clássicas e Doutor em Letras *
}

Se o Continente de São Pedro do Rio Grande do Sul tem chamado a atenção da gente do Rio de Janeiro, do Norte e dos reinóis que, em missōes militares ou civis, vieram em fins do séc. 18 para o extremo sul do Brasil, então isso refere-se, em especial, a palavras e expressões em uso aqui.

Não é uma afirmação leviana; possuimos glossários, datados do último quartel do séc. 18, os quais corroboram essa afirmação e nos fornecem informações preciosas sobre o linguajar gaúcho.

Os primeiros figuram na Descrição à Viagem do Rio Grande, data de 1777. Seu autor é Francisco Ferreira de SOUZA cirurgião-mor do 1 ? Regimento do Rio de Janeiro; ele acompanhou, em 1773, a sua unidade da Guanabara até Laguna por mar e, daí até a Fronteira do Norte (a atual São José do Norte), por terra.

A essa Descrição. . . estão apensos dois glossários:

Termos com os Quais Explicam as Cores dos Cavalos e Termos de Pernuncia pelos que se Explicam os Naturais do Rio Grande e todo o Continente, Rio Pardo e Viamão.

Outro glossário pode ser compilado do famoso Diário Resumido de José de SALDANHA, data de 1787. O Dr. José de SALDANHA foi membro da la. Divisão de Demarcação da América Meridional e chegou ao Rio Grande em 1784. Seu Diário Resumido não apresenta um glossário em anexo. As palavras que nos interessam figuram no tẹto e em notas ao pé da página.

Para dar ao leitor uma idéia da importância desses glossários para a dialetologia gaúcha, transcrevo, primeiro, os glossários de Francisco Ferreira de SOUZA conservando a grafia original; os termos foram colocados em ordem alfabética, mas figuram sem as definições e sem comentários.

Termos com os Quais Explicam as Cores dos Cavalos:

"Professor Catedrático de Filologia Românica, Departamento de Lingüística e Filologia, Instituto de Letras, Universidade Federal do Rio Grande do Sul;

Professor de Lingüística, Departamento de Lingüística e Filologia, Instituto de Letras, Universidade Federal do Rio Grande do Sul;

Professor do Curso de Pós-Graduação em Letras, Instituto de Letras, Universidade Federal do Rio grande do Sul ;

Professor de Dialectologia no Curso de Pós-Graduação em Lingüística, Pontifícia Universidade Catolica do Rio Grande do Sul. 
"Colorado, douradilho, entrepelado, libuno, lubruno, malacara, melado, mouro, oveiro, pangaré, sabino, sapirosa, tordilho claro, tordilho negro, tostado, zaino"

Termos de Pernuncia pelo que se Explicam os Naturais do Rio Grande do Siil a todo o Continente, Rio Pardo e Viamão:

"Acolherado, aguaxar, animais (cavalos), aniquilado, arreata, arrear, "arrejar, asado, banhado, *boleyar, "bombeyro, caixeta, campiar, "campista, capim, caracu, earanciar. cargueyro, carnear, "carretame, combros, bom cômodo, comxavear, ereoviar, "corraleiro, égua madrinha, empantanar, "encorralado, escazular, esparfamar-se, estancia, favoreça o cavalo, fazer parelhas, flaco, folheiro, gatear, goam10. gonsca, guasquear, ligar, lonquiar, macega, madre do corpo, mãe do corpo, maniado, matreiro, matungo, mundongo, sahio parado, pialar, "picota, Iango, potranca, potreiro, rebencar, rebenque, redomão, rengo, rincão, rodar, parar iodeyo, sincha, sinchar, ter a soga, soquete, sovar, ataca no mas, tambeyro, tanguai. terneiro, treixo, tropim, "xarqueada, xucro", (Os termos assinalados com asteriseas foram retirados do texto).

Do Diário Resumido de José de SALDANHA extraí a lista das palavras se-

Nleado (gado), baguais, bolapé, bolas, campestre, camuati(m), canhadas, canoas, apim, eopins (cupins), correntino, durasnal, gauches, laço, lixiguana, lizar(ligar?), lamba, macoga, minuanos (vento), pelotas, portenho, potreiro, rancho, restinga, reilit. rinefo, rodeo, salços (salsos), serros (cerros), tacuru, toropi, vaqueano, xu-

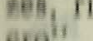

Somando os termos constantes dos dois glossários de Francisco Ferreira de 14. Anexos à Descrição à Viagem do Rio Grande, aos extraídos do Diario Relo José de SALDANHA, obteremos o número impressionante de 126 tertanil do linguajar gaúcho, documentados no último quartel do séc. 18 e, após 200 1001, anda em uso no Rio Grande do Sul Provam isso abonações nos vocabulário ferentes a termos gaúchos de: CORUJA Romaguera CORREA, Roque CALLA (i) IIsCHAUER, Luís Carlos de MORAES, Piaguaçu CORREA, Zeno e Rui Cardain NUNES

Ineontramos ainda esses termos em glossários apensos a obras de Darcy AMiIUIA, Manoel do CARMO, Lassance CUNHA, João Cezimbra JAQUES Amaro IUVENAL, Barbosa LESSA, Luis Carlos LESSA, Alfredo Costa MACHA1) Io Io MENDES, Manoelito de ORNELAS, Vieira PIRES, Apolinário PORTO A I GIRI, Nitheroy RIBEIRO, J. Simões Lopes NETO, Mozart Pereira SOARES, Milie io IIIXEIRA e outros.

A persistência desses termos é deveras um fato extraordinário e de grande portineia para a dialetologia gaúcha.

$\mathrm{A}$ isso acresce outra observação. Embora não tenha sido intenção de FrancisIerreira de SOUZA ele grafou, pelo ouvido, alguns termos, para ele estranhos, pronuneia riograndense de então e que continua sendo a atual. Trata-se, em espede verbos registrados nos vocabulários com o final do infinitivo em - ear: cam Eoreovear, lonquear, pealar. Esse final passa na pronúncia usual do gaúcho pain, pronunciando-se : campiar, corcoviar, lonquiar, pialar. Também maneado é muneiado maniado; cômoros, combros; fraco, flaco, pronúncias já registradas Franeiseo Ferreira de SOUZA.

Trinta e uma palavras constantes nas duas listas acima, o que perfaz $25,8 \%$,

Organon, Porto Alese, is (15):47.50, 1986. são geralmente dadas com sendo castelhanismo. A isso induz a fronteira comum com o Uruguai e a Argentina, países de língua espanhola, sendo os uruguaios chamados de castelhanos pelos rio-grandenses.

Mas em verdade são palavrạs de origem ibérica comum, pertencentes a área ergológica rio-platerise a que, pela conformação do solo e as atividades pastoris tam bém pertence à campanha do Rio Grande do Sul. Apenas um exemiplo: a nossa pala vra "alazão" existe no Uruguai e na Argentina sob a forma de "alazón". A palavra é documentada no português do séc. 13 sob a forma de "alaxam", do árabe ibérico "al'azá'ár".

A mesma conformação do solo, os mesmos aspectos ergológicos, o amálgama das três raças, do índio, do português e do espanhol, do qual resultou aqui o gaúcho e lá o gaucho, fixaram um vocabulário típico, sendo tarefa inútil querer catar castelhanismos em nosso falar rio-grandense, pois essas palavras têm origem ibérica ou ameríndia e circulam tanto no Rio Grande do Sul como no Uruguai e na Argentina.

\section{BIBLIOGRAFIA CITADA E NOTAS}

1 SALDANHA, José. Diario Rezumido e Histórico, ou Relação Geográfica das Marchas e Observações Astronomicas, com algumas Notas sobre a Historia Na tural, e do Paiz. Primeira Divisão da Demarcação da A mérica Meridional. Campanha 4? de 1786-1787. Debaixo da inspeção do Brigadeiro Sebastião Xavier da Veiga Cabral da Camara. Governador do Rio Grande de S. Pedro, e Princiapl Comissario.

Encontra-se na Biblioteca Nacional, Rio de Janeiro, Manuscritos 10, 4, 1. p. 621-734, 114 páginas escritas.

Transcrito em: ANAIS DA BIBLIOTECA NACIONAL. Rio de Janeiro, $v$ 51, p.137-301, 1 mapa (existe separata), 1938.

No Correio do Povo, de Porto Alegre, de 6, 13, 20 e 27 de fevereiro e 2, 5, 12 e 19 de março de 1960, Walter SPALDING publicou uma compilação de todos os termos explicados no tex to ou em notas do Dírío Rezumido e Histórico. aos no texto ou em notas do Liário Kezumido e Histórico.

2 SOUZA, Francisco Ferreira de. Discrição a Viagem do Rio Gre. Offericida à Phylaucima. e Venustima. Snra. Fama perpetua da Duracm. 1777.

Temos de Francisco Ferreira de SOUZA dois manuscritos: um, existente na Biblioteca Pública de Évora, Portugal, (Códice manuscrito CXVI/1-2), com 58 páginas e três planos aquarelados, que é a primeira parte; outro, que figura na Biblioteca Geral da Universidade de Coimbra (Códice manuscrito 148, Papéis Vários, Fls. 139 ss.), com 55 páginas que prossegue além daquela primeira parte e em que figuram os glossários.

Foram editados por Abeilhard BARRETO em Anais do Simpósio do Bicentenário da Restauração do Rio Grande (1776-1976). Rio de Janeiro, Institu to Histórico e Geográfico Brasileiro e Instituto de Geografia e História Militar do Brasil, 1979. v.3 
Guilhermino CESAR [Guilhermino Cesar da Silval, cm Primeiros (ironistas do Rio Grande do Sul 1605-1801, publicado em Porto Alegre pela liaculdade de Filosofia da Universidade Federal do Rio Grande do Sul em 1969 (231p.), transcreve o final do manuscrito da Biblioteca Geral da Universidade de Coimbra (p.154-7). Chama ele a atenção sobre Francisco Ferreira de SOUZA como au tor da mais antiga coleção de vocábulos e frases características da região gaúcha, sem porém transcrevê-la.

Endereço para correspondência: Rua Marques do Pombal, 564/202 90450 Porto Alegre, RS, Brasil. 